International Journal of Advanced Statistics and Probability, $4(1)(2016) 11-15$
International Journal of Advanced Statistics and Probability
WPC
Website: $\begin{gathered}\text { www.sciencepubco.com/index.php/IJASP } \\ \text { doi: } 10.14419 / \text { ijasp.v4il.5667 } \\ \text { Research paper }\end{gathered}$

\title{
Stochastic renewal process model for maintenance (case study: thermal electricity generation in Sudan)
}

\author{
Mohammedelameen Eissa Qurashi *, Ahamed Mohamed Abdalla Hamdi \\ Sudan University of Science \& Technology, Faculty of Science, Department of Statistics \\ *Corresponding author E-mail: wedalameen81@gmail.com
}

\begin{abstract}
The renewal process define as a counting process where the times between the count renewals is a random variables and their distribution is identical. In the electricity generation machines there are spare parts replaced due to damage or expired and replacement process occur repeatedly and the renewal process of here assume that times between replacements are independent random variables and it has identical probability distribution. In this paper, renewal process model has applied on the time of fault for machine in Bahri Thermal Station for electricity generation, which is belong to the National Electricity Authority in Sudan during the period (2011-2015). Through the renewal process model estimation is clear that, the failure time (renewal) for the machines follow Weibull distribution with 2-parameters and when the time trend has been tested it is clear that no trend exist which mean that the renewal process represent Homogeneous Poisson Process (HPP), and the repair rate (renewal) is occurred constantly. In addition, the findings approve that whenever the repair rate (renewal) increase the mean time between failures (MTBF) increases too and this clear in machine no (6).
\end{abstract}

Keywords: Renewal Process; Homogeneous Poisson Process (HPP); Mean Time between Failures (MTBF); Rate of Occurrence of Failure (ROCOF); Weibull; Maintenance.

\section{Introduction}

The electricity power in the past and still the main concern of this world, since it is the backbone of life and the fuel that runs the process of civilization, so the need has grown continuously, and it became a measure of the evolution of nations and advancement because there are some consumers who do not bear any interruption in the electricity so the energy should be insure in a high degree of reliability for these consumers. The paper basic problem of this paper is that there is no model explain the fault machines status, and when we apply the renewal process model on electrical obstetrics machine this leads to a significant improvement in the quality of machine and ensures that the electricity voltage stability by providing a database for decision makers

The objectives of the study to build renewal process model on the machines, generate electricity in Sudan, predict the length of time required for the replacement process, database configuration of the machines in terms of number of faults per year, month and the number of replaced parts, and predict the number of renewals.

The data of this study have been collocated for five machines with exceptional to the machine no (2) because it did never have fault in duration of the study. The sample size has been determine according to the method that not tided to the number of time of failure occurs condition for each machine. The technical fault data collected from the efficiency department in the station and it was (type of machine, time of stopping, time of return, failure time, time between failure and another failure, and power loss) during the period (2011-2015). There are two types of faults: mechanical faults and the faults due to preventive maintenance, in this study we applied the data of mechanical faults.

This study based on the following hypotheses:
- The generation of electricity and the process of replacing parts follow the Poisson regenerative process.

- The time of spare parts replacement follows Weibull distribution.

- There is a relationship between the time of renewal and times of renewal distribution.

\section{Theoretical framework}

\subsection{Renewal process model}

A renewal process is more case of Poisson process in which the inter-arrival time of the process or the time between failures do not necessarily follow the exponential distribution. For convenience will called the occurrence of an event a renewal, the interarrival time the renewal period, and the waiting time the renewal time.

Accounting process $\mathrm{N}(\mathrm{t})$ represent the total number of occurrences of an event in the time interval $(0, t)$ is called renewal process, if time between failure are independent and identically distribution random variable then the probability that are exactly $\mathrm{n}$ failures occurring by time $\mathrm{t}$ can be written as [1]

$\mathrm{P}[\mathrm{N}(\mathrm{t})=\mathrm{n}]=\mathrm{p}[\mathrm{N}(\mathrm{t}) \geq \mathrm{n}]-\mathrm{p}[\mathrm{N}(\mathrm{t})>\mathrm{n}]$

Not that the time between the failure are $\mathrm{T}_{1}, \mathrm{~T}_{2}, \ldots, \mathrm{T}_{\mathrm{n}}$ so that failure occurring at $\mathrm{W}_{\mathrm{k}}$

$\mathrm{W}_{\mathrm{k}}=\sum_{\mathrm{i}=1}^{\mathrm{k}} \mathrm{T}_{\mathrm{i}}$ 


$$
\mathrm{T}_{\mathrm{k}}=\mathrm{W}_{\mathrm{k}}-\mathrm{W}_{\mathrm{k}-1}
$$

And

Thus

$\mathrm{P}[\mathrm{N}(\mathrm{t})=\mathrm{n}]=\mathrm{p}[\mathrm{N}(\mathrm{t}) \geq \mathrm{n}]-\mathrm{p}[\mathrm{N}(\mathrm{t})>\mathrm{n}]$

$=\mathrm{p}\left[\mathrm{W}_{\mathrm{n}} \leq \mathrm{t}\right]-\mathrm{p}\left[\mathrm{W}_{\mathrm{n}+1} \leq \mathrm{t}\right]$

$=F_{n}(t)-F_{n+1}(t)$

Where $F_{n}(t)$ is cumulative distribution function for the time of $\mathrm{nth}$ failure and $\mathrm{n}=0,1,2, \ldots$

The mean value function of a renewal process denoted by $\mathrm{m}(\mathrm{t})$, is equal to sum of distribution function of all renewal time that is

$\mathrm{m}(\mathrm{t})=\mathrm{E}[\mathrm{N}(\mathrm{t})]=\sum_{\mathrm{n}=1}^{\infty} \mathrm{F}(\mathrm{t})$

The renewal function can be obtained as

$$
\begin{aligned}
& m(t)=E[N(t)] \\
& =\sum_{n=1}^{\infty} n p\{N(t)=n\} \\
& =\sum_{n=1}^{\infty} n p\left[F_{n}(t)-F_{n+1}(t)\right] \\
& =\sum_{n=1}^{\infty} F(t)
\end{aligned}
$$

The mean value function of renewal process is also is called the renewal function [1].

\subsection{Homogeneous poisson process (HPP)}

If a system in service can be repaired to a good new condition following each failure, then the failure process is called a renewal process. For renewal process, the time between failures are Independent and identically distributed.

A special case of this is the homogeneous passion process (HPP) Which has Independent and exponential time between failures. Accounting process is homogenous Poisson process with parameter $\lambda>0$ if:

1) $\mathrm{N}(0)=0$

2) The process has Independent increments.

3) The number of failures in any interval of length t is distributed as a Poisson distribution with parameter $\lambda$.

There are several implications to this definition of the Poisson process. The probability mass function of the distribution with parameter $\lambda\left(\mathrm{t}_{1}, \mathrm{t}_{2}\right)$ therefore is:

$\mathrm{p}\left[\mathrm{N}\left(\mathrm{t}_{2}\right)-\mathrm{N}\left(\mathrm{t}_{1}\right)=\mathrm{n}\right]=\frac{\left[\lambda\left(\mathrm{t}_{2}-\mathrm{t}_{1}\right)\right]^{\mathrm{X}} \mathrm{e}^{-\lambda\left(\mathrm{t}_{2}-\mathrm{t}_{1}\right)}}{\mathrm{n} !}$

The expected number of failures by time $t$ is $E[(t)=\lambda(t)=\lambda t=\Lambda$ (t) where $\lambda$ is often called the failure intensity or rate of occurrence of failure (ROCOF). $u(t)=\Lambda^{\prime}(t)=\lambda$ The intensity function is therefore $\mathrm{u}(\mathrm{t})=\lambda(\mathrm{t})=\lambda$ if $\mathrm{X}_{1}, \mathrm{X}_{2}, \ldots$ are identically corresponds to Poisson process [2].

\subsection{Repair rate or $\mathrm{ROCOF}$}

A different approach is used for modeling the rate of occurrence of failure incidences for a repairable system. These rates are called repair rates. Time is measured by system power-on-hours from initial turn-on at time zero, to the end of system life. Failures occur as given system ages and the system is repaired to a state that may be the same as new, better, or worse. The frequency of repairs may be increasing, decreasing, or staying at a roughly constant rate.

Let $\mathrm{N}(\mathrm{t})$ be a counting function that keeps track of the cumulative number of failures a given system has had from time zero to time t. $N(t)$ is a step function that jumps up one every time a failure occurs and stays at the new level until the next failure. Every system will have its own observed $\mathrm{N}(\mathrm{t})$ function over time. If we observed the $\mathrm{N}(\mathrm{t})$ curves for a large number of similar systems and "averaged" these curves, we would have an estimate of $\mathrm{M}(\mathrm{t})$ $=$ the expected number (average number) of cumulative failures by time $t$ for these systems. The derivative of $M(t)$ denoted $m(t)$ is defined to be the Repair Rate or the Rate of Occurrence of Failures at t or ROCOF [4].

\subsection{Test for the time trend and repair effect}

First, the Laplace test is utilized in testing for the time trend, and the repair. The hypothesis is expressed as:

$\mathrm{H}_{\mathrm{o}}$ : No time trend exist (HPP)

$\mathrm{H}_{1}$ : Time trend exist (NHPP)

For Laplace test given $r$ repair $T_{1}, T_{2}, \ldots, T_{r}$ and censoring time tend $>\mathrm{T}_{\mathrm{r}}$ we calculate the statistic:

$$
\mathrm{T}=2 \sum_{\mathrm{i}=1}^{\mathrm{r}} \ln \frac{\mathrm{Tend}}{\mathrm{T}_{\mathrm{i}}}
$$

This test statistic follows a standard normal distribution, this test is recommended for the case when the choice is between trend exist (HPP) and trend not exist (NHPP) [3].

\section{5: Estimation parameter for weibull distribution}

Let $t_{1}, t_{2}, \ldots, t_{n}$ be a random sample from Weibull distribution with p.d.f [3]

$f\left(t_{1}, t_{2}, \ldots, t_{n}, \alpha, \beta\right)=\alpha \beta t^{\alpha-1} e^{-\beta t^{\alpha}}$ For $t \geq 0$

The likelihood function is

$$
\begin{aligned}
& \mathrm{L}\left(\mathrm{t}_{1}, \mathrm{t}_{2}, \ldots, \mathrm{t}_{\mathrm{n}}\right)=\alpha \beta \prod_{\mathrm{i}=1}^{\mathrm{nn} \mathrm{t}_{\mathrm{i}}{ }^{\alpha-1} \mathrm{e}^{-\beta \mathrm{t}_{\mathrm{i}}^{\alpha}}} \\
& \ln \mathrm{L}\left(\mathrm{t}_{1}, \mathrm{t}_{2}, \ldots, \mathrm{t}_{\mathrm{n}}\right)=\mathrm{n} \ln \alpha+\mathrm{n} \ln \beta+(\alpha-1) \sum_{\mathrm{i}=1}^{\mathrm{n}} \ln \mathrm{t}_{\mathrm{i}}-\beta \sum_{\mathrm{i}=1}^{\mathrm{n}} \mathrm{t}^{\alpha}
\end{aligned}
$$$$
\frac{\partial \ln L}{\partial \alpha}=\frac{\mathrm{n}}{\alpha}+\sum_{\mathrm{i}=1}^{\mathrm{n}} \ln \mathrm{t}_{\mathrm{i}}-\beta \sum_{\mathrm{i}=1}^{\mathrm{n}} \mathrm{t}^{\alpha} \ln \mathrm{t}_{\mathrm{i}}=0
$$$$
\frac{\partial \ln L}{\partial \beta}=\frac{\mathrm{n}}{\hat{\beta}}+\sum_{\mathrm{i}=1}^{\mathrm{n}} \mathrm{t}_{\mathrm{i}}{ }^{\alpha}=0
$$

Thus, the maximum likelihood estimation of $\alpha$ and $\beta$ are

$$
\hat{\beta}=\frac{n}{\sum_{i=1}^{n}\left(\frac{t}{t_{i}}\right)}
$$




\section{Application aspect}

The application aspect includes to what explained in the theoretical aspect and we would describe the data, test the distribution of the data, estimate renewal process model and comparison between machine in repair rate and MTBF.

\subsection{Description of failure times}

The study will be described for the failure time, for the five machines with some descriptive measures in order to know the nature of study's data type.

Table 1: Rates of Failure Times for Each Machine

\begin{tabular}{lllll}
\hline \multicolumn{5}{c}{ Table 1: Rates of Failure Times for Each Machine } \\
\hline Machine & Mean (hr) & Std. (hr) & $\begin{array}{l}\text { 95\% C.I. for Mean } \\
\text { Lower }\end{array}$ & Upper Bound \\
\hline Machine no(1) & 6.764 & 9.249 & 9.249 & 10.217 \\
Machine no(3) & 6.442 & 9.023 & 9.023 & 9.153 \\
Machine no(4) & 6.747 & 11.808 & 11.808 & 9.263 \\
Machine no(5) & 8.528 & 10.719 & 10.719 & 13.545 \\
Machine no(6) & 15.451 & 15.174 & 15.174 & 22.552 \\
Mean & 7.720 & 11.374 & 11.374 & 9.298 \\
\hline
\end{tabular}

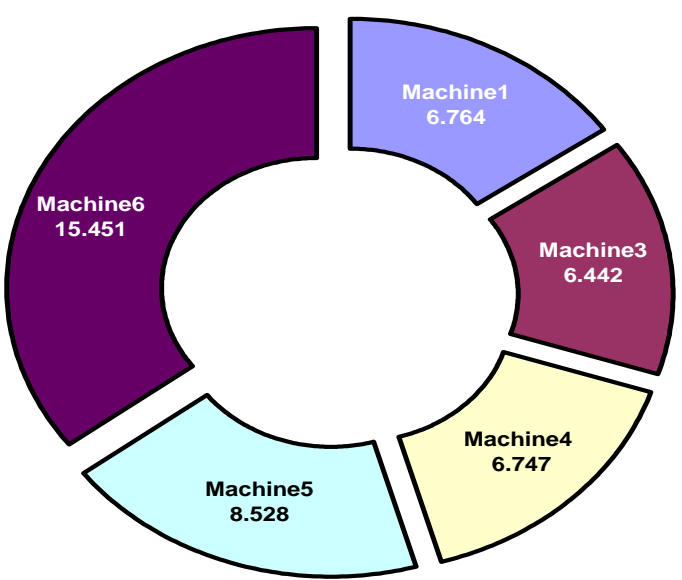

Fig. 1: Rates of Failure Times for Each Machine.

From above table and figuer, it has shown that according to the mean values for the five machines ,the machine (6) have the highest mean failure depending on the value of the largest mean (15.45) hours, followed by machine (5) depending on the value of the second largest mean (8.53) hours, followed by machine (1) depending on the value of the third largest mean (6.76) hours, lastly machine (1) and machine (4) (6.76) and (6.75) respectively.

\subsection{Test of data distribution}

Here we test the following hypothesis:

$\mathrm{H}_{\mathrm{o}}$ : The failure data follow Weibull distribution

$\mathrm{H}_{1}$ : The failure data follow Weibull distribution

Table 2: Kolmogorov-Smirnov Test for Machines

\begin{tabular}{llll}
\hline Machine & Statistic & $\mathrm{n}$ & $\mathrm{P}$-value \\
\hline Machine no(1) & 0.23796 & 30 & 0.05595 \\
Machine no(3) & 0.13482 & 44 & 0.47132 \\
Machine no(4) & 0.13482 & 84 & 0.41859 \\
Machine no(5) & 0.27464 & 23 & 0.05035 \\
Machine no(6) & 0.2479 & 44 & 0.1439 \\
\hline
\end{tabular}

From above table, it shows the p-value of Kolmogorov-Smirnov test of all machines is greater than significant level (0.05) that mean the failures time data follow Weibull distribution with 2parameters.

\subsection{Renewal process model}

For estimation renewal process model, we must test the time trend whether exist or not, and determine if the process represent homogeneous Poisson process (HPP) or non-homogeneous Poisson Process (NHPP), used Laplace test as:

$\mathrm{H}_{\mathrm{o}}$ : No time trend exist (HPP)

$\mathrm{H}_{1}$ : Time trend exist (NHPP)

Table 3: Laplace Test for Machines

\begin{tabular}{lll}
\hline Machine & Statistic & P-value \\
\hline Machine no(1) & 1.39377 & 0.163387 \\
Machine no(3) & 1.90625 & 0.056617 \\
Machine no(4) & 1.84127 & 0.065582 \\
Machine no(5) & 1.74100 & 0.081684 \\
Machine no(6) & 1.97223 & 0.058582 \\
\hline
\end{tabular}

From above table, it shows the p-value of Laplace test for all machine is greater than significant level $(0.05)$, that mean no time trend exist and the process is HPP, that means rate of renewals (repair) of machines is constant, the following table shows estimate of renewal process model:

From the table (4), it has shown that, the ROCOF for machine no (1) equal (0.149246) and MTBF equals (6.70036) renewals (repairs), for machine no (3) ROCOF equal to (0.119365) and MTBF equal to (8.37763) renewals, for machine no (4) ROCOF is equal to (0.161706) and MTBF is equal to (6.18406) renewals, for machine no (5) ROCOF is equal to (0.12573) and MTBF is equal to (7.95355) renewals, and lastly for machine no (6) ROCOF is equal to (0.60552) and MTBF is equal to (16.5139) renewals (repair).

Table 4: Result of Renewal Process Model for Machines

\begin{tabular}{|c|c|c|c|c|}
\hline \multirow[b]{2}{*}{ Machine } & \multicolumn{2}{|c|}{ Renewal process parameter } & \multirow[b]{2}{*}{ Renewal rate (Repair) } & \multirow[b]{2}{*}{ MTBF } \\
\hline & $\hat{\alpha}$ & $\hat{\beta}$ & & \\
\hline Machine no(1) & .9164570 & 6.43011 & .1492460 & 6.70036 \\
\hline Machine no(3) & 0.771699 & 7.19846 & .1193650 & 8.37763 \\
\hline Machine no(4) & 0.947382 & 6.0346 & .1617060 & 6.18406 \\
\hline Machine no(5) & 0.978765 & 7.88332 & .125730 & 7.95355 \\
\hline Machine no(6) & 1.10631 & 17.1464 & .605520 & 16.5139 \\
\hline
\end{tabular}

Table 5: Mean Cumulative Renewals Process Model

\begin{tabular}{llccc}
\hline \multirow{2}{*}{ Time } & \multicolumn{4}{c}{ Mean cumulative renewal } \\
Machine no(1) & Machine no(3) & Machine no(4) & Machine no(5) \\
\hline 0 & 0.0000 & 0.0000 & 0.0000 & 0.0000 \\
80 & 11.9397 & 9.5492 & 12.9365 & 10.0584 \\
160 & 23.8794 & 19.0984 & 25.8730 & 20.1168 \\
240 & 35.8190 & 28.6476 & 38.8094 & 30.1752 \\
320 & 47.7587 & 38.1968 & 51.7459 & 40.2336 \\
400 & 59.6984 & 47.7460 & 64.6824 & 50.2920 \\
\hline
\end{tabular}




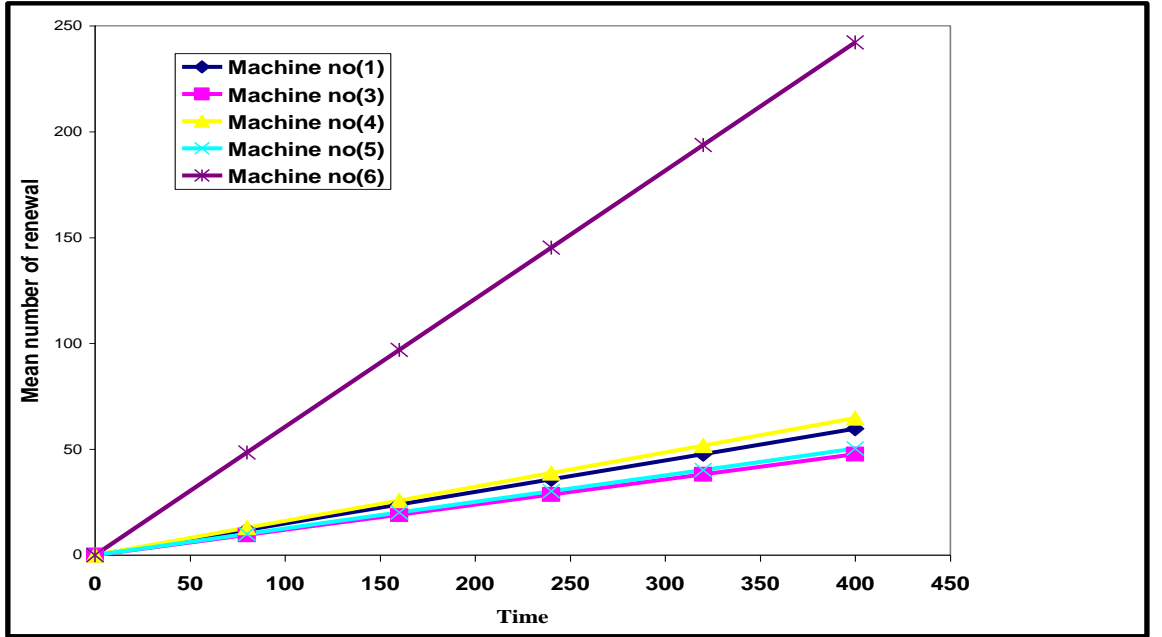

Fig. 2: Mean Cumulative Number of Renewal vs. Time 3.4: Test of Goodness of Fit Test Model.

$\mathrm{H}_{\mathrm{o}}$ : The underlying distribution of the renewal process is Weibull $\mathrm{H}_{1}$ : The underlying distribution of the renewal process is not Weibull

Table 6: Goodness of Fit Test Model

\begin{tabular}{lll}
\hline Test & Statistic & P-value \\
\hline Machine no(1) & 0.186259 & 0.249717 \\
Machine no(3) & 0.200644 & 0.0578703 \\
Machine no(4) & 0.151492 & 0.052323 \\
Machine no(5) & 0.188084 & 0.394419 \\
Machine no(6) & 0.161352 & 0.675058 \\
\hline
\end{tabular}

From above table, it has shown the p-value of KolmogorovSmirnov of the all machine is greater than significant level (0.05) that mean the underlying distribution of the renewal process is Weibull, indicates that the time of replacing parts is stationary Poisson regenerative process.

\subsection{Comparison between machines}

We compare the four machine according to renewal process model. we compare, renewal rate (repair), mean time between renewals

Table 7: MTBF and Renewal Rate (Repair) Comparison

\begin{tabular}{lll}
\hline Machine & Renewal rate (Repair) & MTBF \\
\hline Machine no(1) & .1492460 & 6.70036 \\
Machine no(3) & .1193650 & 8.37763 \\
Machine no(4) & .1617060 & 6.18406 \\
Machine no(5) & .125730 & 7.95355 \\
Machine no(6) & .605520 & 16.5139 \\
\hline
\end{tabular}

From above table, and according to the renewal rate (repair) and the MTBF, the machine no (6) achieved high renewal rate it was about (0.61) with MTBF equal to (17 hours), it followed by the machine no (3) which has the second high renewal rate it was (0.16) with MTBF equal to (6 hours), then the machine no (1) in third level acording to high value for the renewal rate which was about (0.14) with MTBF equal to (8 hours). The machine no (5) was in the fourth level acording to fourth high value for the renwal rate it was about (0.13) with MTBF equal to (8 hours). Lastly, the machine no (3) acording to the low value for the renewal rate which was about (0.12) with MTBF equal to (8 hours).

\section{Conclusions}

The main findings of this paper are:

The most important results of this study are:

1) Time of failures follows Weibull distribution with 2parameters for five machines.
2) No time trend exist for the failure time and renewal process (repairable) which represent homogeneous passion process (HPP) for the five machine.

3) The repairable time of machines represent Poisson stationary regenerative process.

4) The underlying distribution of the renewal process is Weibull.

5) The repair rate of machines occurred constantly.

6) There is a relationship between repair rate and mean time between failures (MTBF), which means whenever repair rate increases the mean time of period between faults increases in too.

7) The predication of the number of renewals reveals that the number of renewal increase in linearity for all machines.

\section{Acknowledgement}

I would take this opportunity to thank my research supervisor Dr. Ahamed Mohamed Abdalla Hamdi. Special thanks to our great teacher and my idle role Also my thanks to (Dr. Bassam Younis Ibrahim Ahamed, Head of Statistics \& Research Section Strategic Planning Division Abu Dhabi,UAE) Engineer Khalid Eltahir Abdall-Basit and my friend Mr. Mohammed Omer Musa for their support and guidance without which this research would not have been possible.

\section{References}

[1] Honag Pham (2006), System Software Reliability, the State University of New Jersey, USA, Springer.

[2] Adamantios Mettas \& Wenbiao Zhao (2005), Modelling and Analysis of Repariable System with General Repair, IEEE Annual RELIABILITY and MAINTAINABILITY Symposium.

[3] Huairui R.Guo, Haitao Liao, Wenbiao Zhao \& Adamantios Mettas (2007), an A New Stochastic Model for Systems under General Repair, IEEE Transaction on Reliability, Vol. 56. http://dx.doi.org/10.1109/TR.2006.890895.

[4] Jan A. Van Casteren (2013), Advanced Stochastic Processes.

[5] Richard Serfozo (2009), Basics of Applied Stochastic Processes, Springer. http://dx.doi.org/10.1007/978-3-540-89332-5.

[6] Mario Lefebvre (2007), Applied Stochastic Processes, Springer.

[7] Van Noortwijk, J.M. \& Klatter, H.E. (2004), the use of Lifetime Distributions in Bridge Maintenance and Replacement Modeling, $\begin{array}{llll}\text { Computers and } & \text { Structures, }\end{array}$ http://dx.doi.org/10.1016/j.compstruc.2004.03.013.

[8] Rackwitz, R. (2001), Optimizing Systematically Renewed Structures, Reliability Engineering and System Safety, Vol. 73. http://dx.doi.org/10.1016/S0951-8320(01)00050-3.

[9] Yanez, M., Joglar, F, \& Modarres, M.( 2002), Generalized Renewal Process for Analysis of Repairable systems with limited failure experience, Reliability Engineering and System Safety, Vol. 77. http://dx.doi.org/10.1016/S0951-8320(02)00044-3. 
[10] Savits, T. H. (1988), a Cost Relationship between Age and Block Replacement Policies, Journal of Applied Probability, Vol. 25. http://dx.doi.org/10.2307/3214300.

[11] Bo Bergman (1978), Optimal Replacement under a General Failure Model, Advances in Applied Probability,Vol. 10. http://dx.doi.org/10.2307/1426944.

[12] Van Der, J.A., Weide, S. \& Van Noortwijk, J.M., (2008), Renewal Theory with Exponential and Hyperbolic Discounting. Probability in the Engineering and Informational Sciences, Vol. 22.

[13] Aven, T. \& Gaarder, S. (1987), Optimal Replacement in a Shock Model: Discrete Time, Journal of Applied Probability, Vol. 24. http://dx.doi.org/10.2307/3214082.

[14] Huairui R. Guo, Haitao (2007), ANew Stochastic Model for Systems Under. General Repairs, IEEE TRANSACTIONS ON RELIABILITY, VOL. 56, NO. 1.

\section{Appendix}

Failure Data for Five Machines during Period (2011-2015)

\begin{tabular}{|c|c|c|c|c|}
\hline $\begin{array}{l}\text { Failure time } \\
\text { Machine } \\
\text { no(1) }\end{array}$ & $\begin{array}{l}\text { Machine } \\
\text { no(3) }\end{array}$ & $\begin{array}{l}\text { Machine } \\
\text { no(4) }\end{array}$ & $\begin{array}{l}\text { Machine } \\
\text { no(5) }\end{array}$ & $\begin{array}{l}\text { Machine } \\
\text { no(6) }\end{array}$ \\
\hline 0 & 768 & 0.95 & 5.98 & 24 \\
\hline 48 & 48 & 24 & 528 & 288 \\
\hline 24 & 192 & 24 & 48 & 1.73 \\
\hline 1704 & 1008 & 648 & 1608 & 65.87 \\
\hline 504 & 240 & 120 & 5.98 & 7.77 \\
\hline 48 & 10.98 & 240 & 528 & 35.43 \\
\hline 14.38 & 72 & 120 & 48 & 11.85 \\
\hline 2.20 & 2496 & 264 & 1608 & 20.78 \\
\hline 8.92 & 336 & 24 & 1.32 & 18.25 \\
\hline 1.42 & 192 & 4 & 10.53 & 27.43 \\
\hline 30.18 & 2.45 & 120 & 2.07 & 2.17 \\
\hline 30.53 & 3.40 & 168 & 5.53 & 10.03 \\
\hline 1.42 & 0.00 & 312 & 28.80 & 3.50 \\
\hline 2.75 & 3.43 & 144 & 13.68 & 11.95 \\
\hline 4.50 & 0.82 & 24 & 0.95 & 3.00 \\
\hline 7.77 & 2.3 & 96 & 21.25 & 9.22 \\
\hline 36.47 & 3.25 & 144 & 1.95 & 5.42 \\
\hline 1.05 & 14.90 & 288 & 1.77 & 10.33 \\
\hline 1.80 & 5.33 & 96 & 7.75 & 6.47 \\
\hline 7.77 & 2.02 & 48 & 2.15 & 10.13 \\
\hline 2.85 & 4.08 & 168 & 4.82 & \\
\hline 1.58 & 42.27 & 456 & 1.92 & \\
\hline 3.62 & 2.77 & 576 & 22.55 & \\
\hline 1.70 & 4.17 & 96 & 41.58 & \\
\hline 1.97 & 29.65 & 168 & 1.22 & \\
\hline 4.03 & 1.77 & 96 & 9.35 & \\
\hline 1.21 & 0.98 & 264 & 16.65 & \\
\hline 0.88 & 3.88 & 192 & 31.17 & \\
\hline 2.77 & 23.53 & 48 & 16.27 & \\
\hline \multirow[t]{34}{*}{3.50} & 1.67 & 672 & 6.30 & \\
\hline & 1.17 & 288 & 3.83 & \\
\hline & 2.77 & 1.30 & 2.78 & \\
\hline & 4.67 & 0.95 & 10.67 & \\
\hline & 1.30 & 2.12 & 5.98 & \\
\hline & 1.08 & 1.73 & 2.02 & \\
\hline & 17.22 & 0.95 & 2.07 & \\
\hline & 0.78 & 4.73 & 2.65 & \\
\hline & 7.18 & 6.27 & 1.53 & \\
\hline & 12.77 & 10.33 & 1.93 & \\
\hline & 10.22 & 73.83 & 5.47 & \\
\hline & 1.77 & 3.93 & 2.83 & \\
\hline & 14.37 & 1.38 & 2.85 & \\
\hline & 0.88 & 4.82 & 0.8 & \\
\hline & 7.32 & 1.40 & 13.73 & \\
\hline & 0.83 & 2.97 & 3.62 & \\
\hline & & 8.45 & 5.30 & \\
\hline & & 8.92 & & \\
\hline & & 3.95 & & \\
\hline & & 1.68 & & \\
\hline & & 1.67 & & \\
\hline & & 3.23 & & \\
\hline & & 2.73 & & \\
\hline & & 4.28 & & \\
\hline & & 3.52 & & \\
\hline & & 18.07 & & \\
\hline & & 20.67 & & \\
\hline & & 3.25 & & \\
\hline & & 0.92 & & \\
\hline & & 2.70 & & \\
\hline & & 0.0 & & \\
\hline & & 5.53 & & \\
\hline & & 2.67 & & \\
\hline & & 3.07 & & \\
\hline
\end{tabular}

Source: Bahri Thermal Station, Efficiency department, 2015 